TITLE:

\title{
The Anatomy of the Pacific Oyster, Crassostrea gigas (Thurnberg)(Bivalvia : Ostreidae)
}

\section{$\operatorname{AUTHOR}(S):$}

Evseev, G. A.; Yakovlev, Yu. M.; Li, Xiaoxu

\section{CITATION:}

Evseev, G. A.... [et al]. The Anatomy of the Pacific Oyster, Crassostrea gigas

(Thurnberg) (Bivalvia: Ostreidae). PUBLICATIONS OF THE SETO MARINE BIOLOGICAL LABORATORY 1996, 37(3-6):239-255

ISSUE DATE:

1996-12-25

URL:

http://hdl.handle.net/2433/176265

RIGHT: 


\title{
The Anatomy of the Pacific Oyster, Crassostrea gigas (Thurnberg) (Bivalvia: Ostreidae)
}

\author{
G.A. EvSEeV, Yu. M. YakovleV \\ Institute of Marine Biology, Far East Branch, Russian Academy of \\ Sciences, Vladivostok 690041, Russia \\ and \\ XIAOXU LI \\ Institute of Oceanology, Academia Sinica, \\ Qingdao 266071, P.R. China
}

\begin{abstract}
The anatomy of the soft body parts of the Pacific oyster Crassostrea gigas is presented. Anatomical features of mantles, gills, labial palps, pericardial cavity, heart, oesophagus, stomach, gastric shield, crystalline style sac and intestine are described in detail. These structure in $C$. gigas are compared with those in closely related species. We suggest that some anatomical features provide taxonomic characteristics that may be used to distinguish $C$. gigas from morphologically similar species within and between genera.
\end{abstract}

Key words: Crassostrea gigas, soft organ morphology, taxonomy

\section{Introduction}

The morphological features of the shells have been used extensively in oyster taxonomy. However, the utility of shell features in oyster taxonomy is limited by the high level of their intra-specific variation (Tchang Si \& Lou Tze-Kong, 1956; Menzel, 1973). The use of shell structural features in oyster taxonomy is particularly problematic between morphologically similar species from the genera Crassostrea and Saccostrea. For example, in the Sea of Japan, the Pacific oyster Crassostrea gigas is frequently confused with morphologically similar species of the genera Crassostrea and Saccostrea.

Differences in the anatomy of the internal organs of bivalves have shown promise as taxonomic characteristics. For example, Pelseneer (1903) found that the structure of branchiae and other soft organ characteristics could be used to separate bivalve classes. Nelson $(1938,1960)$ found that differences in the structure of the promyal chamber and labial palp morphology could be used to identify oyster species of the genus Ostrea.

We suggest that differences in the anatomical features of the internal organs may provide a means of distinguishing $C$. gigas from morphologically similar species within or among genera. Therefore, in this paper, we describe the anatomical features of soft organs of $C$. gigas and compare them with those of morphologically similar species of the genera Crassostrea and Saccostrea.

\section{Materials and Methods}

Specimens of Crassostrea gigas (Thunberg) were collected from the intertidal or sub-intertidal zone of Amur Bay, the Sea of Japan. Gastric shields were dissected from some specimens at the time of collection, as these structures deteriorate rapidly if they remain within the animals whilst their values are closed. Specimens were then preserved in either $4 \%$ formalin or $70 \%$ alcohol for subsequent dissection and description. Oriental sections, free-hand crosses, sagittal longitudinal 


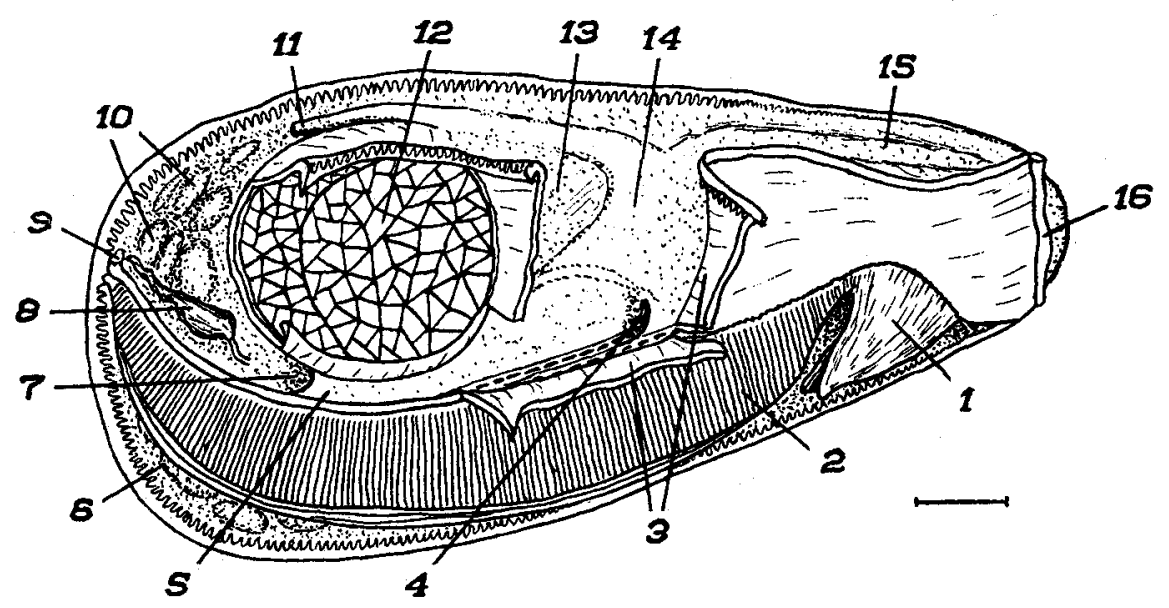

Fig. 1. Mantle cavity and topography of the internal organs (right mantle lobe has been cut partly). 1, labial palp; 2, gills; 3 , right mantle lobe; 4 , entrance to the right inner epibranchial chamber; 5 , pyloric process; 6 , left mantle lobe; 7 , entrance to the left epibranchial chamber; 8 , left accessory heart; 9 , posterior mantle fusion; 10 , mantle sacs; 11 , anus; 12 , adductor muscle; 13 , pericardial cavity; 14 , promyal passage; 15 , antero-dorsal mantle cavity; 16 , anterior mantle fusion. Scale: $1 \mathrm{~cm}$.

sections or organ dissections were prepared, some of which were stained with Boemer's hematoxylin. Figures were drawn with the aid of a dissecting microscope.

\section{Descriptions}

The soft part of $C$. gigas consists of four sections, the visceral mass (anterior), the adductor muscle (central), the gills (ventral) and the two asymmetric mantle lobes (lateral). Each of these sections is described below.

\section{The mantles}

The mantles of Crassostrea gigas cover, and fuse partly with the visceral mass laterally, and fuse with each other anteriorly (subligamental isthmus) and posteriorly (gill-mantle junction) (Fig. 1). On right side, there is a broad channel, the promyal passage, lying between the adductor and the visceral mass and connecting the right epibranchial cavity with the dorsal cavity. Based on their structures, morphologies, locations and functions, the mantles of this oyster can be divided into three parts: the thick mantle, the thin mantles and the marginal mantles.

The thick mantle extends from anterior to the adductor to the visceral mass, and is characterized by the well developed loose connective tissues which contains transversally distributed muscle filaments, a loosely scattered blood vessel network and a thin layer of diagonal muscle filaments just beneath the epithelium.

The thin mantles, being mainly located around the adductor muscle, consist of one subepithelial muscle layer and one or two diagonal middle muscle layers, and contain large nerve branches blood vessels and complicated lacunas. The patterns of the loos connective tissues nearby the adductor differ from the rest in having muscle bundles radiating from the adductor towards the mantle margins. Near the margins these bundles branch and join the lateral branches from otehr bundles, and are overlapped by the concentric muscle filaments 
parallel to the mantle edges.

The mantle margins, which consist of the dorsal, ventral and posterior mantle lobe borders, have three folds. The outer fold is smooth and separated from the adjacent fold by a periostracal groove. The anterior of middle fold looks like a swollen ridge with rugate lateral zones. The distal edge of the anterior portion is decorated with one row of short papillae, whereas the posterior portion is supplied with two to three rows of papillae, of which the first is situated on the distal end of the fold and consists of long papillae with swollen tips, the second is short and located on the inner side of the first, its papillae lie at the intervals between the papillae of the first, the third one is very similar to the second, but its papillae are much shorter and can only be found along the posterior-most of the mantles. The inner fold has one row of papillae on its crest. The size and morphology of these papillae changes along the length of the fold. Papillae located near to the labial palps look like low widely separated denticles. Papillae located along the ventral portion of the mantles are of two types; those at the anterior end are straight and long with short papillae alternately scattered; those along the posterior region are longer and closely set and have rows of small knobs on their tops.

The inner surfaces of the mantle lobes are covered by a ciliated epithelium, their posterior and ventral regions are sometimes scattered with semi-globular or elliptical sacs which connect to blood vessels through the narrow slits.

\section{The mantle cavity}

Inside the shells two mantle lobes form a semiclosed space which is divided by the gills into two communicated chambers, the extended entrance chamber, which occupies the ventral and the posterior regions, and the cloacal chamber. The cloacal chamber is subdivided by the adductor muscle and the gills into (1) the posterior cavity, which occupies the space dorsally to the branchial base and posteriorly to the adductor muscle, (2) the epibranchial cavity, which consists of two inner and two outer epibranchial subcavities, (3) the narrow dorsal cavity, which occupies the space dorsally to the adductor muscle, and (4) the promyal passage, which extends, at the right side, between the dorsal cavity and the right epibranchial cavity.

\section{The mantle cavity organs}

\subsection{The gills}

The regularly distributed plicae of the gills are each composed of 10-12 ordinary filaments and 2 thickened principal filaments, of which the latter are situated in the interplicate grooves. The filaments are composed of skeletal rods and blood vessels encircled by the connective tissues, and are joined each other laterally by the interfilamentous bridges which form series of rectangular vellulae with a narrow interfilamentous passage, the ostium, at the centres. These bridges could be seen easily from the internal cavities and have, in cross sections, a canal which is surrounded by the longitudinal muscle fibres. The demibranches of each gill are united by the interlamellar septa at the principal filaments forming dorsoventrally oriented passages, the water tubes, which leave four series of branchial openings at the branchial base, gradually decreasing in diameter towards the gill free (ventral) ends. Near the branchial bases the interlamellar septa usually connect with the principal filaments at $4-6$ intervals.

The broad branchial base inside the epibranchial chamber bears 5 longitudinal crests. The middle crest connects ventrally with the adductor and the visceral mass and forms a longitudinal septum, which divides the epibranchial chamber into two chambers, the left and the right epibranchial chambers. Each of the two chambers is, at the anterior end, subdivided into two by the lateral septum formed by the crests adjacent to the middle crest, resulting in 
A

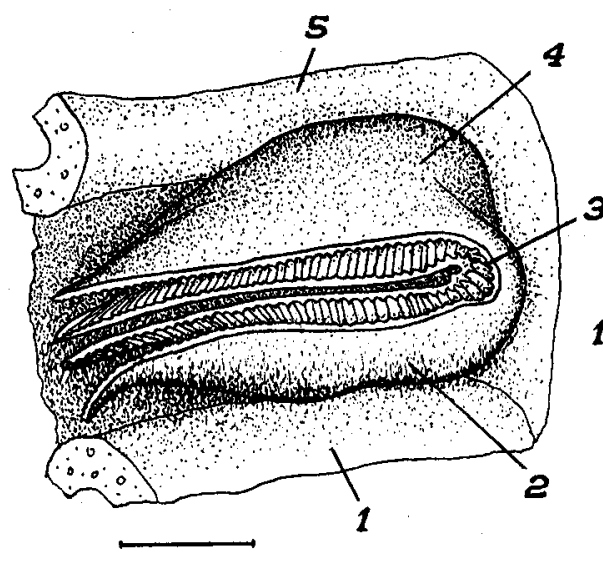

B

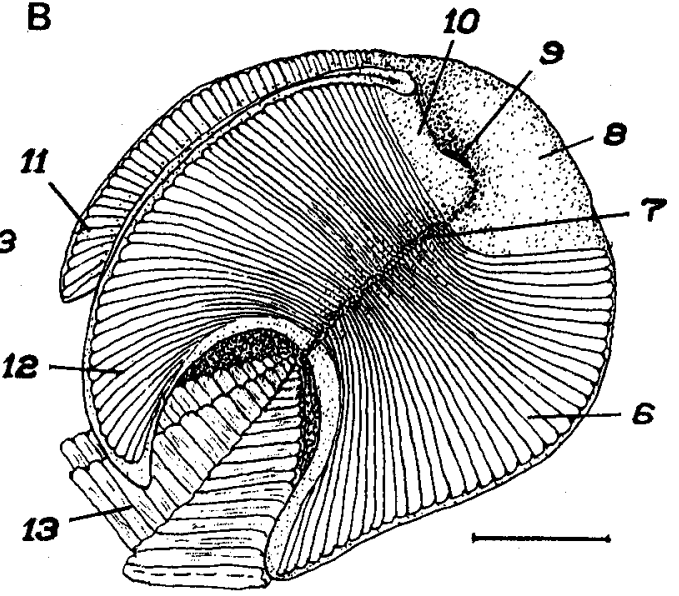

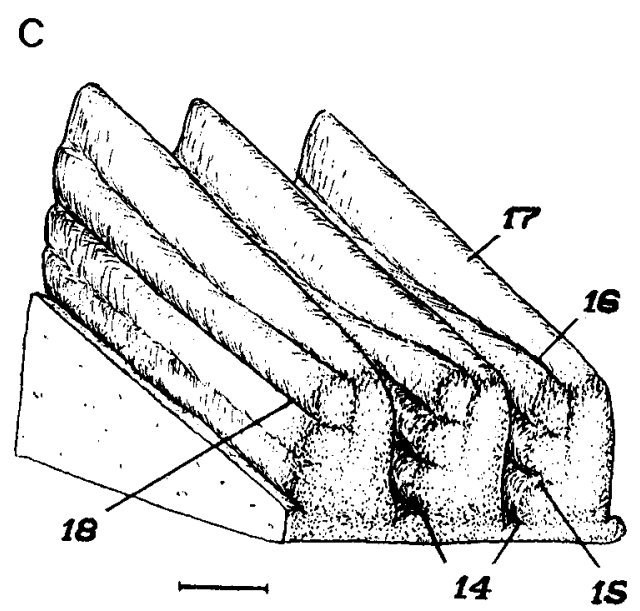

Fig. 2. Labial palps. (A) Ventral view. (B) Side view (partly opened). (C) Sorting crests. 1, left mantle lobe; 2 , outer labial palp; 3 , entrance to the mouth; 4 , right portion of the outer palp; 5 , right mantle lobe; 6 , left sorting area of the outer labial palp; 7, food groove; 8 , perioral area of the outer palp; 9 , mouth; 10 , perioral area of inner palp; 11, right sorting area of the outer palp; 12 , left sorting area of the inner palp; 13 , gills; 14, the fourth (lower) groove; 15, the third groove; 16 , the first groove; 17 , top of crest; 18 , the second groove. Scales: $1 \mathrm{~cm}$.

2 inner and 2 outer sub-chambers. These sub-chambers narrow towards the anterior end and terminate inblind tubes. The right lateral septa is shorter than the left lateral septa.

\subsection{The labial palps}

The labial palp plates are asymmetrical, with the outer left palp plate being large and the outer right plate being small. The labial palp fuse with the visceral mass and the mantles at the proximal ends, but are free at the distal ends (Fig. 2). The inner surface of the outer palp and the outer surface of the inner palp are covered with the sharp regular crests which begin at the distal edge, cross the palp surface and merge into the proximal food grooves extending between the mouth and the collecting grooves of the gills. The height and the width of the 


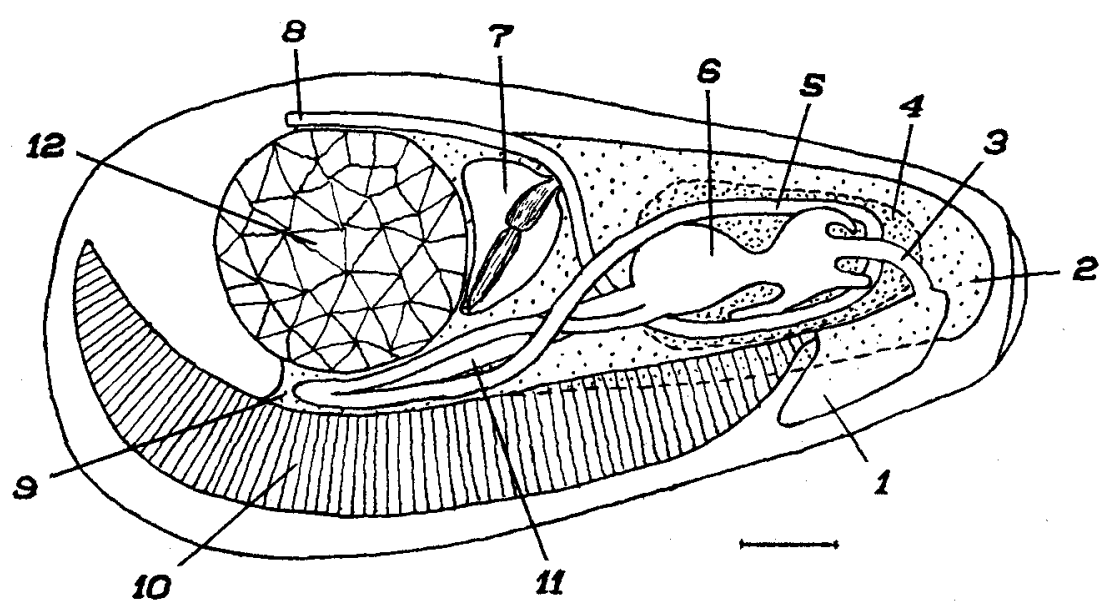

Fig. 3. Topography of visceral mass organs. 1, labial palps; 2, visceral mass; 3 , oesophagus; 4, diverticular gland; 5 , midgut; 6 , stomach; 7 , pericardial cavity with ventricle and auricles; 8 , anus; 9, pyloric process; 10 , gills; 11 , crystalline style sac; 12 , adductor muscle. Scale: $1 \mathrm{~cm}$.

crests increase proximally. The distal edges of the palp are free from the marginal field or food groove, but covered with the sorting crests.

The oral slopes of the sorting crests bears 4 delicate grooves which differ in length and depth. The first (apical) groove runs along the oral side of the crest half way from the distal end. The second (middle) groove extends from the distal to the proximal ends. The third groove can be clearly traced only half way from the distal end and connects with the fourth (basal) groove which lies along the base of the crest and runs toward the perioral field.

The sorting field on the posterior end of palp is bordered by two marginal grooves. The first is connected with the food groove between palps and gills, the second fringes the posterior palp edge and goes into the perioral palp field covered with ciliated epithelium and decorated by the fine radial ruggers which converge toward the mouth split. The ruggers are more obvious on the outer palp, especially on the borders between the perioral field and the sorting field. The ruggers on the inner palp begin near the distal edge, run toward the mouth and bifurcate into two broad grooves which join the mouth split at the corners. The triangular field formed between the grooves is covered with fine ripple-like grooves parallel to the mouth split.

\section{The organs in the visceral mass}

The visceral mass is composed of the circulartory organs, the digestive organs and the reproductive organs. The anatomy of these organs are described below (Fig. 3).

\subsection{The pericardial cavity}

The pericardial cavity lies anterior to and shares the posterior wall with the adductor muscle, and is rectangular or rounded in shape (Fig. 4). The pericardial cavity consists of one ventricle and two auricles.

The ventricle is triangular, compressed, and covered with fine nodules and small ruggers. It narrows anteriorly into two aortas lying one under the another (seen after dissection of the cavity), the dorsal one turns left-dorsally and goes toward the adductor muscle along the wall 
A

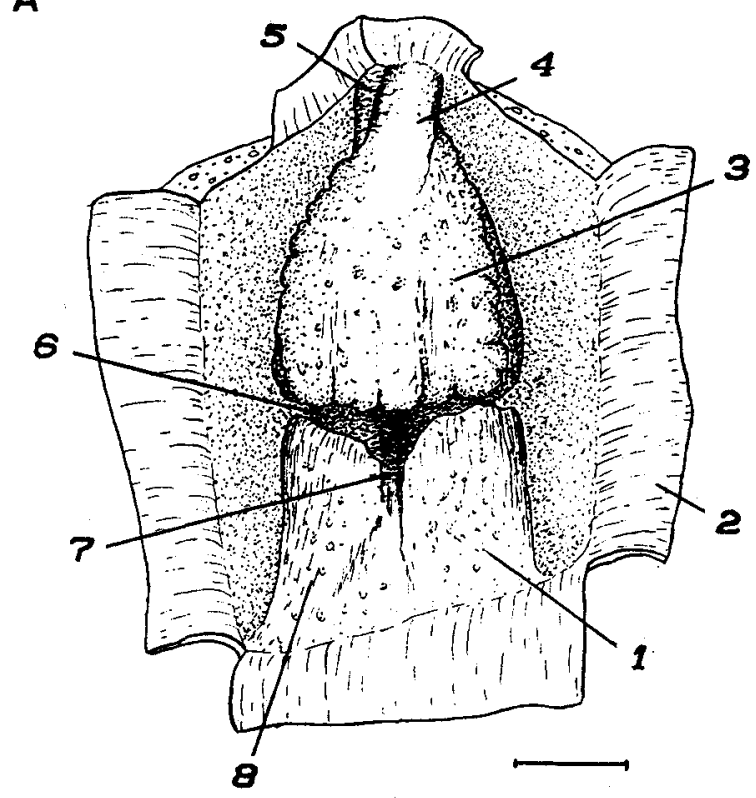

C

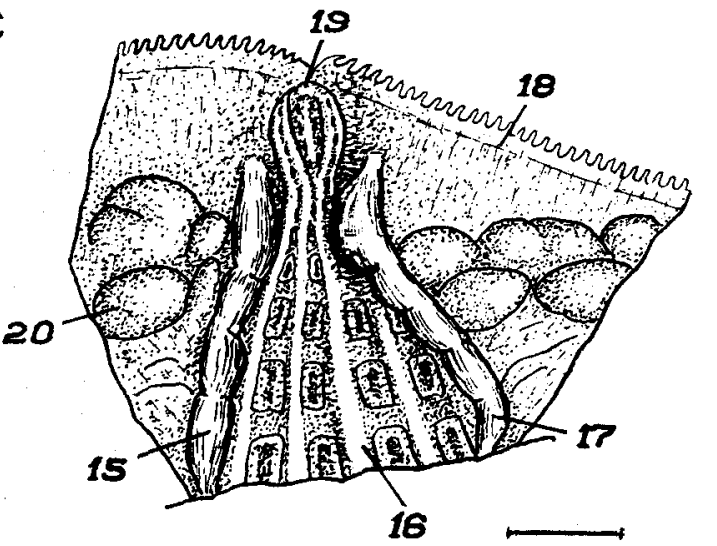

B

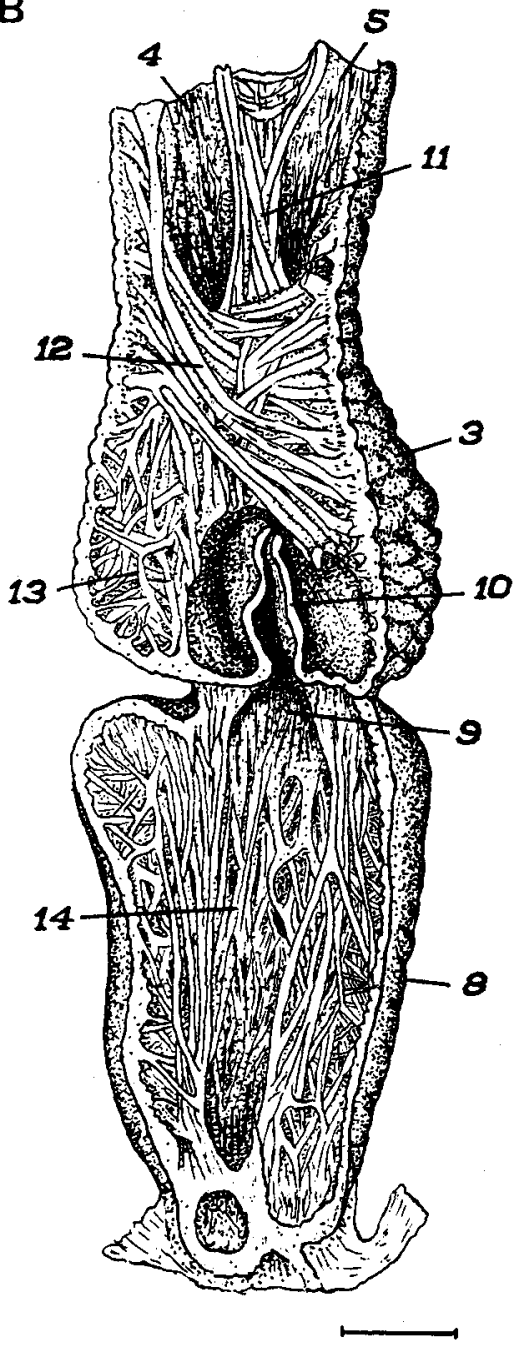

Fig. 4. (A) Dorsal view of the pericardial cavity. (B) Longitudinal section of the ventricle and left auricle. (C) Accessory heart. 1, right auricle; 2, dorsal pericardial wall; 3, ventricle; 4, posterior aorta; 5, anterior aorta; 6, auriculo-ventricular narrow; 7, inter-auricular slit; 8 , left auricle; 9 , auriculo-ventricular channel; 10 , left valve; 11 , longitudinal myocardial fibres; 12 , diagonal fibre bands; 13 , fibre branches; 14 , longitudinal myocardial fibres of auricle; 15 , right accessory heart; 16 , central crest; 17 , left accessory heart; 18 , posterior mantle margin; 19, posterior mantle fusion; 20 , mantle sacs. Scales: $1 \mathrm{~cm}$.

of the cavity, the ventral one passes through the cavity and goes anteriorly with its main vessels.

Two sac-like auricles, which lie parallel to each other and are fused with each other by the posterior lateral walls, are connected with the posterior part of ventricle by the atrialventricular narrows and adhere to the posterior corners of the pericardial cavity by the outer 
posterior edges. The outer surfaces of auricles are covered with longitudinal ruggers, fine nodules and irregular knots. The left auricle is usually larger than right auricle after formalin fixation.

The internal structures of the ventricle and auricles are similar in some features. Their walls are made of two layers: the outer dense epicardial tissues and the inner myocardial fibre net. The terminations of the net fibres are usually fused together irregularly and connected with the outer layers.

The myocardial fibres of the auricles are fine and round in cross sections. Most of them run longitudinally and branch into an anastomosous net near the walls. But the axial spaces in auricle centres are nearly free from fibres.

At the posterior ends, the auricles are connected, through broad apertures, with branched blood vessels coming mainly from the adductor muscle, kidneys, mantle lobes and gills.

The outer dense epicardial tissues of the ventricle are thinner than that of the auricles. The fibres of the myocardial fibre net can be divided into three types: the short branching fibres, which form dense nets of trabeculae at the posterior part of the ventricle; the fused longitudinal bundles, which form, at anterior part, the semiporous septum between aorta orifices; and the diagonal or radial bands. The posterior wall bears two slit-like atrialventricular openings, the edges of which are stretched out internally and form highly specialized plates which serve as valves to prevent reversing blood current. The fibre free cavities are found around the valves and the aorta.

Two accessory hearts, which are found on the mantle lobes of the epibranchial chamber, are connected with blood system through their anterior and posterior openings. The anterior opening unites with the longitudinal pallial vessels of the epibranchial cavity, which can be traced toward the mantle areas near the pyloric process, whereas the posterior opening is merged with tubes from the pallial-branchial junction. In cross section, the external layer of the accessory heart is made of longitudinally thickened nodular crests which are joined together by the semi-transparent thin elastic membranes. The internal layer consists of transversal fibres which gather in bundles at the sides where the accessory heart adheres to the mantles. At the anterior third of the accessory heart, there are, between these bundles, some small openings which are connected by the pallial blood vessels, while at the posterior third of the accessory heart, there is only one opening which is delineated by the sharp crest. In addition, two collateral muscle bundles run internally along the accessory heart-mantle adhesions, which are detached from the walls near the posterior end of the accessory heart, and supported by the radial muscle fibre net and then form a stem fading into the posterior opening.

\subsection{The alimentary system}

The alimentary system includes the oesophagus, stomach, crystalline style sac and intestine (Fig. 5). The stomach is "dumb-bell" shaped and can be divided into two compartments: the anterior compartment, which consists of two caeca and one diverticular pouch, and the posterior compartment, which is larger than the anterior compartment and has a gastric shield bed on dorsal surface and a sac of crystalline style and midgut on ventral surface.

\subsubsection{The oesophagus}

The oesophagus is broad and short, and looks, in cross section, like a narrow and sinous split which, beginning from the mouth, changes its positions in relation to the sagittal plane of the visceral mass from $90^{\circ}$ to about $40^{\circ}$. Internally the oesophagus is covered by ciliated epithelium and decorated by the broad longitudinal folds which turn counter-clockwise when viewed from the mouth. The grooves between folds are again decorated by the fine longitudinal grooves terminating at the apertural crest of the oesophagus. 
A
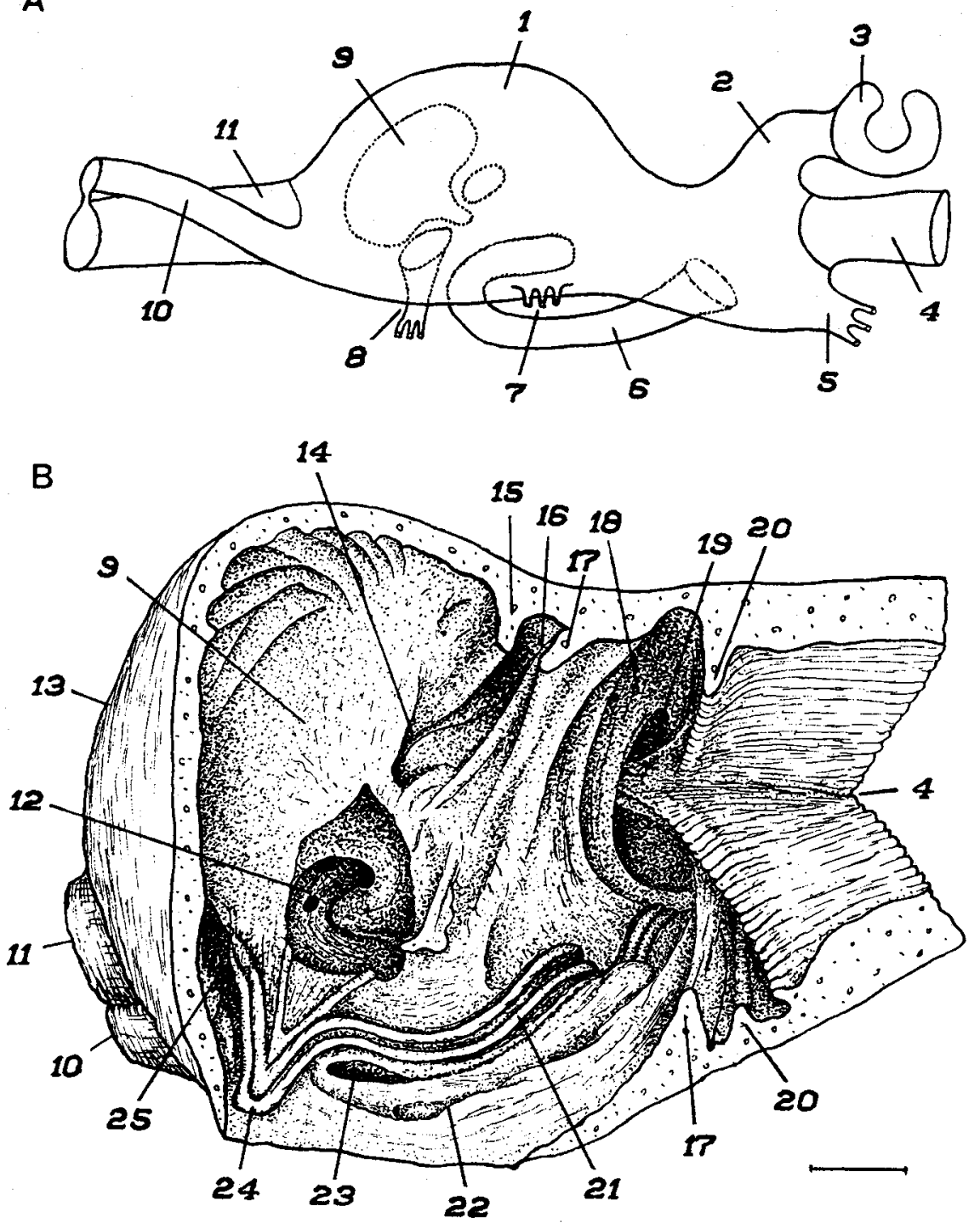

Fig. 5. (A) Schematic structures of the stomach. (B) Inner surface features of the stomach. 1, gastric shield compartment; 2 , anterior (caecum) compartment; 3 , anterior caecum; 4, oesophagus; 5 , anterior embayment; 6, posterior caecum and diverticular ducts; 7, diverticular ducts on right wall; 8, diveticular duct pouch; 9 , bed of gastric shield; 10 , midgut; 11 , crystalline style sac; 12 , digestive pouch; 13, posterior wall; 14 , dorsal hood; 15 , main separating crest; 16 , rejecting groove; 17 , coarse sorting buttress; 18 , crest-like fold between caeca; 19 , entrance to anterior caecum; 20 , dorsal crest of oesophageal aperture; 21, typhlosole; 22, rejecting groove of the right diverticular embayment; 23 , right diverticular embayment; 24 , tongue of the typhlosole; 25 , midgut and crystalline style sac openings. Scale: $1 \mathrm{~cm}$. 

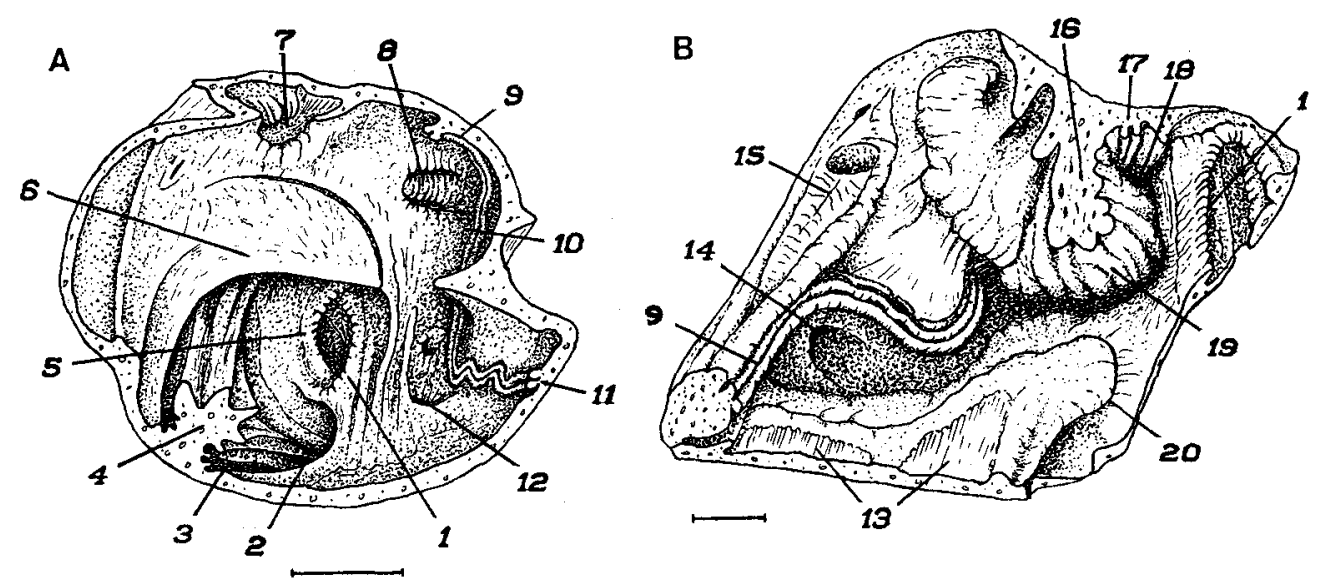

Fig. 6. Stomach and its sorting areas. (A) Anterior wall. (B) Right ventral wall. 1, ventral crest of the oesophageal aperture; 2, left end of the anterior caecum; 3 , typhlosole (extending from anterior caecum to posterior one); 4 , axial fold of the anterior caecum; 5 , dorsal crest of oesophageal aperture; 6 , crest-like fold; 7 , the fourth diverticular duct; 8 , the third diverticular duct; 9 , typhlosole (goes to tongue); 10 , anterior embayment; 11 , typhlosole (extending from posterior caecum to anterior embayment); 12, the first diverticular duct; 13 fine sorting area; 14 diverticular ducts on the right wall; 15 , digestive pouch of the right wall; 16, axial fold (buttress) between compartments; 17 , typhlosole (goes toward the posterior caecum); 18, entrance of the posterior caecum; 19, coarse sorting area; 20, rejecting groove of the right diverticular embayment. Scales: $1 \mathrm{~cm}$.

\subsubsection{The stomach}

\subsubsection{The anterior wall}

The centre of the anterior wall bears the oesophageal aperture surrounded by the marked dorsal and ventral apertural crests (Fig. 6). The dorsal crest begins at the ventral corner of the oesophageal aperture on left wall and ends a little bit anteriorly at the other corner of the aperture on the same wall. The ventral crest, on the other hand, begins at posterior to the dorsal crest end on the right wall, and ends at anterior to the dorsal crest beginning on the same wall. The lateral food grooves in the apertural corners, if viewed from the mouth, run counter-clockwise.

On the left of the oesophageal aperture is the entrance of the horse-shoe-shaped sorting caecum. On the right close to the dorsal crest end is a crest-like high fold extending from ventral to dorsal surface. The anterior wall also forms, ventrally to the oesophageal aperture and the crest-like fold, a depression which extends to the right and terminates with the chamber of the fourth diverticular duct opening.

\subsubsection{The anterior caecum or the horse-shoe-shaped sorting caecum}

This caecum, which occupies the dorsal anterior wall of the stomach, is a cylindrical pouch with a thickened central crest. In cross section, the two ends of the caecum are oriented dorsally, while the central part connects with the stomach through a broad passage. The typhlosole here originates as a groove, then is flanked by two low lateral crests and gradually becomes typical near the caecum entrance. The typhlosole then goes through the dorsal field of the oesophageal aperture to the right end of the caecum, runs along the anterior wall to the left end of the caecum, and leaves the end along the posterior wall. It 
then turns ventrally and at last runs out of the caecum along the left wall toward the posterior caecum.

\subsubsection{The posterior sorting caecum}

The posterior sorting caecum, which is subrectangular in cross sections, is a narrow elongated sac which opens on the ventral wall of the anterior compartment and extends posteriorly under the stomach to the location of the gastric shield, where it turns left first, then dorso-anteriorly and terminates blindly almost half way between the entrance and the posterior bend.

Internally, the caecum has a distinct crest of various heights, being markedly high on the ventral surface of the entrance, but becoming lower toward the posterior band. The caecum entrance bears, on its dorsal wall, a deep groove flanked by two rounded low crests. The three-grooved typical typhlosole can be traced entering the caecum along the left wall while going out along the right wall. So, the typhlosole, together with the dorsal and ventral crests, form a food delivery channel in the caecum.

\subsubsection{The sorting areas in the stomach}

The sorting field consists of two areas with different sorting surfaces: (1) the coarse sorting area, which extends from the anterior wall of the anterior compartment to the entrance of the posterior compartment and covered by series of large folds beginning as low crests of various widths sub-parallel to the oesophageal slit, and (2) the fine sorting area, which is located on the right wall of the posterior compartment, dorsally to the gastric shield bed, ventrally to the diverticular groove and posteriorly to the coarse sorting area, and is covered by regular ridges and grooves.

\subsubsection{The right diverticular chamber}

The right diverticular chamber, which is situated between the fine sorting area and the tongue of typhlosole, is a large recess, into which open five oval apertures of the diverticular ducts (Fig. 7). The posterior two oval apertures are isolated from the rest. The walls of the ducts and the areas between the apertures are covered by the regular deep grooves, some of which go out the diverticular apertures, cross the chamber and join with the collecting groove (the lateral channels accompanying the typhlosole). The collecting groove then turns dorsally, rounds the chamber posteriorly, and goes anteriorly toward the entrance of the posterior caecum.

\subsubsection{The digestive pouch}

The digestive pouch (see Fig. 7B), which lies on the stomach floor, is composed of a deep spiral-conical sac terminated with the diverticular ducts, and can be divided into two compartments, the upper broad compartment, which has a five-cornered entrance, and the lower deep compartment, which is an about $3 / 4$ clockwise turned spiral and is separated from the upper compartment by a shelf-like fold which serves as the gastric shield holder. The outlines of the pouch entrance, especially the left and the posterior-left margins, are modified by the features of the gastric shield. Except the crests which extend between and in the compartments, the walls of the upper compartment are simple. In the lower compartment lie six diverticular duct openings, of which the upmost one is on the anterior wall. From this opening comes a fine crest which goes, via the right wall of the pouch entrance, to the tongue of typhlosole where it merges, at an acute angle, with another posterior crest of the same range but running in opposite direction. The third well marked crest in the pouch, which comes externally from the coarse sorting field, is broadened near the pouch entrance, but becomes narrow when it enters the pouch along the anterior wall, and then fades away at the lower compartment, the groove which accompanies the crest on the right side still goes down, turns right first and then toward the diverticular duct openings. The spiral field on the right 

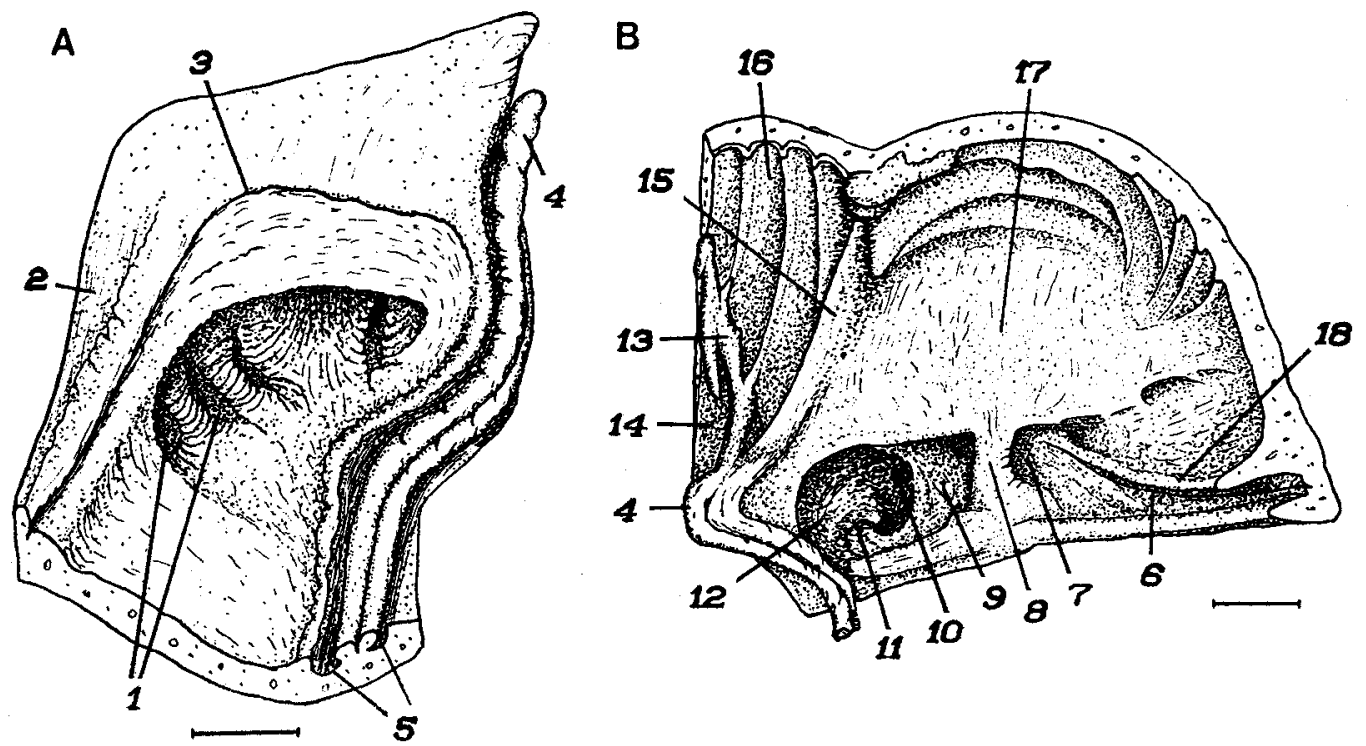

Fig. 7. (A) Right diverticular chamber. (B) Bed of the gastric shield. 1, diverticuar duct openings; 2 , fine sorting area; 3 , rejecting groove of the right diverticular chamber; 4 , tongue of the typhlosole; 5 , Iateral channels of the typhlosole; 6 , rejecting groove of the dorsal hood; 7 , dorsal hood; 8 , saddle-like crest; 9 , upper compartment of the digestive pouch; 10, diverticular openings at lower compartment of the digestive pouch; 11 , spiral crest; 12 , spiral area of the right posterior wall; 13 , extension of the typhlosole between style sac and midgut; 14, midgut; 15 , crest of the apertural sac; 16 , style sac; 17 , meniscus area of the gastric shield bed; 18 , main separating crest. Scales: $1 \mathrm{~cm}$.
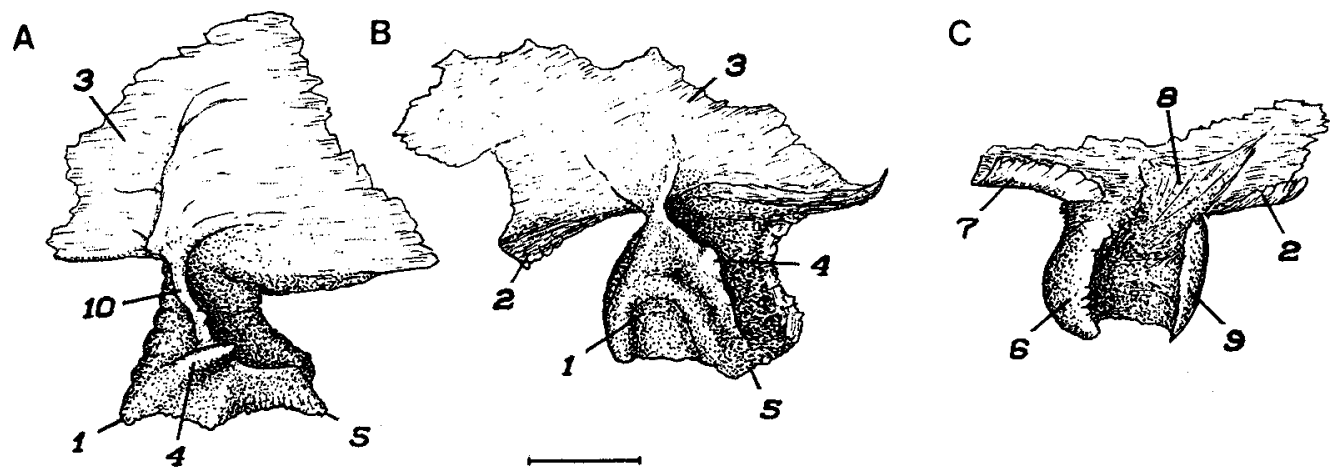

Fig. 8. Gastric shiel. (A, B) Functional sides. (C) Opposite sides. 1, erosive head; 2, anterior edge of the meniscus anchored in digestive pouch; 3 , meniscus; 4 , erosive tooth; 5 , left anterior process of the erosive head; 6 , anchors of erosive head; 7 , anterior edge of the meniscus anchored in dorsal hood; 8 , leaf-like thickening; 9 , grinding crest. Scale: $1 \mathrm{~cm}$. 
wall of the lower compartment, which is restricted by the anterior and the posterior crests, is covered with the fine regular grooves coming from the ducts and narrows gradually away from the ducts.

\subsubsection{The dorsal hood}

The dorsal hood is a small crescent-like depression of the left wall, located anteriorly to the dorsal wing of the gastric shield and left to the saddle-shaped crest, and transforms anteriorly into a broad shallow channel running toward the coarse sorting field. At the bottom of this channel lies a fine groove which extends from the oesophageal apertural field to the centre of the dorsal hood. A further two folds also lie in the channel: the posterior high fold and the anterior fold. The posterior fold starts at the ventral apertural field of the oesophagus. The anterior fold extends from the coarse sorting field to the saddle-shaped crest.

\subsubsection{The gastric shield and the shield bed}

The shield bed occupies nearly half of the posterior compartment and consists of a slightly concave area of the ventral-left wall of the stomach. Its right side is bordered by the apertural crest of the style sac; its posterior side is connected with a field full of folds and broad grooves; its anterior edge is divided into three parts, the right part falls sharply into the diverticular pouch, the left part falls into the dorsal hood, the middle part is fused with a short saddle-shaped crest which separates the pouch and the hood and serves as a base to bear the erosive head of the shield. The centre of the bed, the meniscus, is covered by high dense cilia, and seves to hold the shield.

The gastric shield is a thin semitransparent plate with a thickened erosive head (Fig. 8) which consists of a sharp erosive tooth and a saddle. The saddle, which is fused with the meniscus plate by a leaf-like thickening, looks, in cross section, like a round bracket with acutely folded edges. The functional side of the saddle has a sharp, left oblique ridge (the grinding crest) originating from the anterior-left projection and fading onto the centre of the meniscus, such that the left slope of the ridge becomes precipitous, whereas the right slope becomes gentle, continuing with the functional surface in one specimen, but being separated by a narrow groove in others. In the natural state (i.e. unpreserved) the gastric shield lies with its convex side on the shield bed, and is firmly held by the saddle which is anchored by the saddle-shaped crest of the shield bed, and the meniscus edges which are tucked right in the digestive pouch, left in the dorsal hood.

\subsubsection{The crystalline style sac and the intestine}

After leaving the stomach, the intestine first goes posteriorly to the tapering termination of the pyloric process, sharply curves ventrally, and then goes back along right side toward the stomach in parallel to the style sac. Near the stomach the intestine runs dorsally, circles the stomach, passes across the style sac (the style sac-intestine cross) on left side, goes back dorsally again, instead of circling the stomach it passes dorsally across the pericardial cavity, and finally terminates as a simple anus on the dorsal side of the adductor muscle.

Based on anatomical features, the intestine can be divided into three compartments (Fig. 9). The initial compartment, the midgut, which is the portion from the stomach to the pyloric curvature, is covered by relatively smooth ciliated epithelium and connected with the style sac by a diagonal slit. When opened from the slit, its left wall is bordered by a massive fold, the minor typhlosole, which is covered by the fine diagonal grooves, and terminates at the blind end of the sac, its right wall is margined by the main typhlosole bearing interrupted short fine diagonal grooves, and extending far into the anus. The middle compartment extends from the pyloric termination to the style sac-intestine cross, and is internally decorated by the sharp angular rib-like folds. The typhlosole in this part bears a middle 

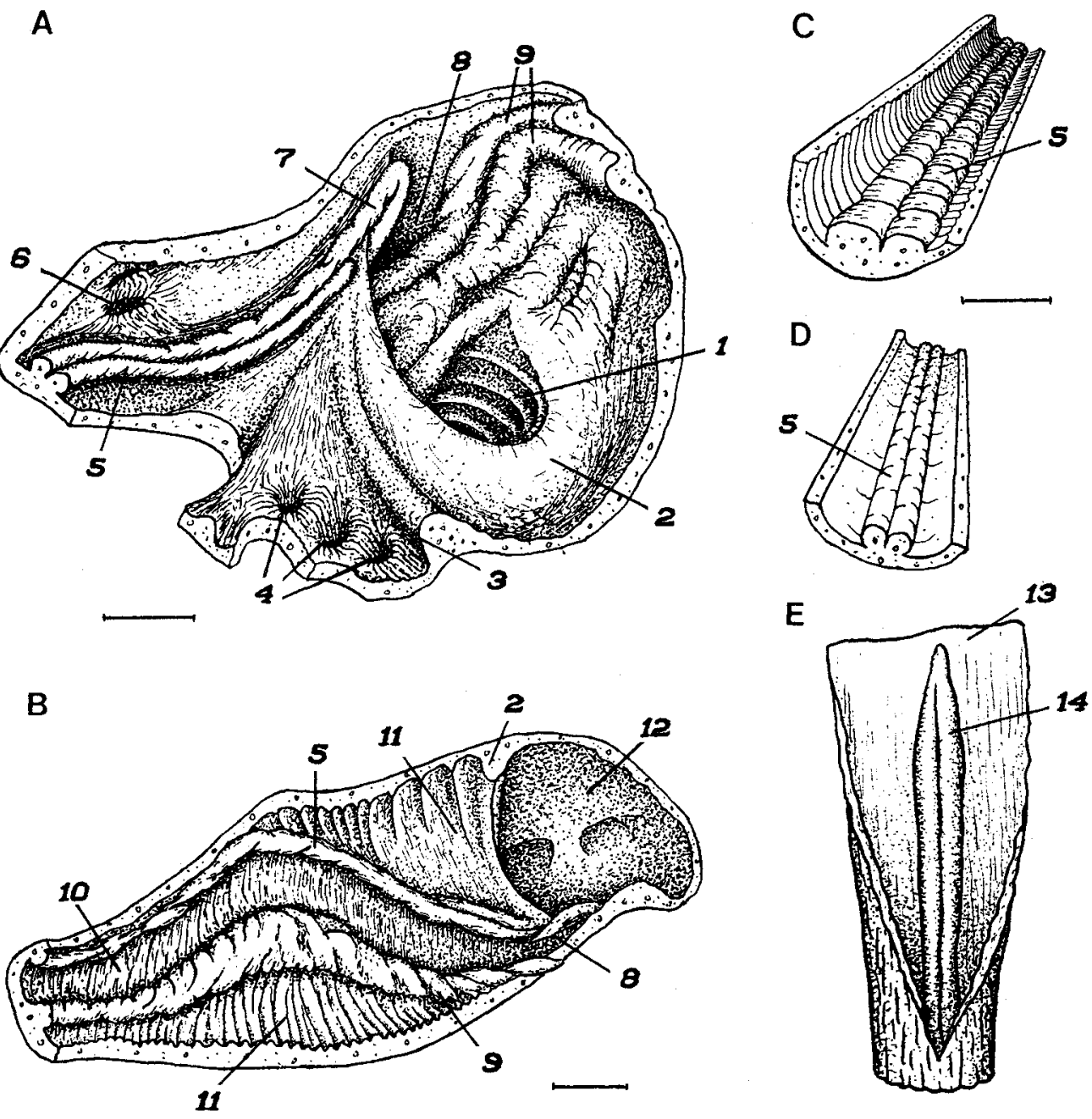

Fig. 9. (A) Openings of the style sac and the midgut. (B, C, D, E) Middle, posterior and anal compartments of the intestine. 1, style sac entrance; 2 , separating crest; 3 , posterior wall of the digestive pouch; 4 , diverticular ducts; 5 , typhlosole; 6 , right diverticular embayment; 7 , tongue of teh typhlosole; 10, food groove at the beginning of midgut (opened from right side); 11 , style sac; 12 , gastric shield bed; 13, anus (partly opened); 14, typhlosole end. Scales: $1 \mathrm{~cm}$.

groove and changes its left-wall position to the right through the ventral surface. Near the stomach the typhlosole becomes broader with the increase in intestine diameter and occupies nearly half of the intestinal clear space and is decorated by the fine cross grooves. The rectal compartment includes the posterior dorsal loop of the intestine from the style sac-intestine cross to the anus. The walls of this region are smooth, and covered by the ciliated epithelium. The typhlosole contains two round, semidetached crests accompanied by three grooves which become more obvious towards the anus.

The crystalline style sac, which extends from the stomach to the end of the pyloric 
process, is a long cylindrical organ accompanied by, and connected by the midgut through a narrow slit. In cross section, the sac, the midgut and the connecting slit look like an asymmetrical "dumb-bell". The positions of the gut in relation to the sac change from right to the sac at the opening to ventral, then left to the sac on the way, and at last dorsal to the sac at the end of the pyloric process.

The openings of both the sac and the midgut are on the posterior wall of the stomach. The style sac opening is separated from the gastric shield bed and the digestive pouch by a high barrier ridge (the apertural crest), which originates from the tongue of typhlosole, goes around the style sac opening, then ends at the posterior wall of the stomach where it is converged with the broad folds from the style sac. The funnel-shaped opening of the midgut is situated posteriorly to the tongue of typhlosole, and is about one third of the diamter of the style sac opening.

Internally, the style sac is decorated with sharp rib-like folds which are separated from each other by the broad smooth spaces which are again, at a distance away from the opening, covered by various ridges.

\section{Discussion}

The genus Crassostrea is comprised of about 8 species. Among them Crassostrea gigas, $C$. virginica and $C$. angulata are widespread, and their soft organ morphology has been well studied. Features of the mantles, especially the mantle folds and their papillae and mantle cavities, bear a high degree of similarity between species of the genus Crassostrea. However, some distinctions in the mantle features of these species have been found. For example, in contrast to $C$. virginica the posterior portion of the right epibranchial cavity in $C$. angulata is constricted as a result of the extension of the right septum (Nelson, 1938). These peculiarities in septa were considered by Harry (1985) as the supra-specific characteristics in Ostreidae, and were reconfirmed by $\mathrm{Li}(1989)$ for their taxonomic importance in species comparison. $\mathrm{Li}(1989)$ found that the right septum in $C$. rivularis is shorter than that in $C$. gigas and $C$. talienwanensis.

The posterior chamber in C. virginica (Galtsoff, 1964) is reduced dorso-posteriorly as compared with that in $C$. gigas in which it, in turn, is less in volume than in $C$. rivularis, similar relationships can also be found between $C$. angulata and $C$. rivularis. However, this eco-morphological feature, if used in taxonomy, should be examined carefully since it has been found to vary considerably in littoral and upper sublittoral oyster species.

The papilla morphology and the papilla arrangement on the middle mantle fold has been used for both species and genus comparisons. For example, Rodriguez \& Garcia-Cubas (1986) used them to classify $C$. gigas, $C$. virginica, C. iridescens and C. rizophorae; Hirase (1930) and Torigoe (1981) discussed them at the generic level. However, Harry (1985) believed that the papillae features are neither species-specific nor generic but family features. Our material shows that the papillae can be used to discriminate some genera, such as Crassostrea, Saccostrea and Ostrea.

The branchial plates of $C$. angulata, $C$. virginica and $C$. gigas are similar, but the plicae in different species may contain a different number of filaments. For example, $C$. virginica has 8-15 (mean 12); C. angulata has 8-14 (mean 12) (Neslon, 1960), the average numebr in $C$. gigas is 12 . Differences can also be found in the arrangements of the interlamellar septa, which are at 4 plica intervals in C. virginica, 6 in $C$. angulata (Nelson, 1938, 1960), and 5 in C. gigas.

The labial palps and their junctions with anterior terminations of branchial plates are reliable generic features in distinguishing Ostrea from Crassostrea (Yonge, 1960; Galtsoff, 1964). However, differences between species in these genera are poorly studied. Nelson 
(1960) has noted some differences between species of Crassostrea in labial palp morphology. Comparing our results from C. gigas with data from C. virginica (Kellogg, 1892; Show \& Battle, 1957) and from C. angulata (Leenhart, 1926) reveals that there are some differences in the sorting crests between species in Crassostrea (see Fig. 2C). Unlike C. gigas which has three minor crests on each crest, the sorting crests in C. virginica, according to Show \& Battle (1957), are composed of two kinds of minor crests. One crest is higher and looks like a shelf on the proximal part ofthe crest, the other is lower and runs along the distal part of the crest. However, according to Galtsoff (1964), the crest of $C$. virginica consists of only one kind of minor crests, the lower minor crests.

Galtsoff (1964) provides a description of the anatomy of the ventricle and auricles of $C$. virginica. Comparison of the anatomy of these structure in $C$. virginica with that in other closely related Crassostrea species indicates that they show a high degree of similarity (see Dahmen, 1923; Hirase, 1930; Torigoe, 1981). Nonetheless, comparisons of the anatomy of the ventricle and auricles of $C$. virginica and $C$. gigas show that differences exist. For example, the auricles in $C$. virginica are fused with each other laterally, while in $C$. gigas they are separated by a narrow slit. Other differences between them include the topography and the structure of the trabecular fibres. Unfortunately, data on the cardial complex in other Crassostrea species does not exist, and therefore inter-specific differences in these structures remain unknown.

As previously described by Hopkins (1934), the accessory heart in C. gigas looks like a thickened pulsating vessel running from the kidney to the posterior mantle junction and branching with 4-5 couples of fine vessels. In $C$. virginica, however, the main vessel has a large branch which runs dorsally toward, and then disappears, near the anus (Galtsoff, 1964). In cross section through the anterior portion of the accessory heart the longitudinal muscle band, which is clear in $C$. gigas, has not been found in $C$. virginica.

The alimentary complex in oysters is usually presented with the schematic drawings of the stomach compartments, the topography of intestine coils and diverticular ducts (Awati \& Rai, 1931; Show \& Battle, 1957; Galtsoff, 1964; Rodriguez \& Garcia-Cubas, 1986; Li \& Qi, 1994). These features are sufficient to distinguish oysters to the level of genus. For example, Saccostrea species are unique in having an appendix, a channel-like area and the lateral folds (Dinamani, 1967). Ostrea species are unique in having a very short oesophagus, one caecum and two latero-diverticular ducts (Graham, 1949). Crassostrea species are characterised by having two caeca, of which one is horse-shoe-shaped, and three series of diverticular openings. However, differences between species within the genus $C$ rassostrea remain unknown due to inadequate descriptions. The published data on anatomy of $C$. virginica and $C$. angulata show little about the fine structures of the stomach, such as transporting grooves, typhlosole, sorting buttress, diverticular chambers, apertural crests and sorting areas (Galtsoff, 1964; Purchon, 1957; Show \& Battle, 1957; Rodriguez \& Garcia-Cubas, 1986).

The importance and usefulness of the internal organ features in oyster taxonomy have been known for more than 50 years (Orton, 1937; Nelson, 1938), and have been stressed in recent works (Torigoe, 1981; Harry, 1985; Li \& Qi, 1994). In addition to the shell morphology and the shell structures, the features usually used to identify genus are: types of early larval development, presence of promyal passage, morphological features of mantle margins, configuration and structure of sorting crests of labial palps, relationships between labial palps and gills, connection between crystalline style sac and midgut, numbers of ordinary filaments per branchial plicae, general morphology of stomach, positions of diverticular chambers, and situations of appendix and typhlosole. The evaluation of internal organ features in interspecific comparison has been attempted in genera Ostrea, Saccostrea, Hyotissa, Crassostrea and Dendostrea (Harry, 1985; Li \& Qi, 1994). Based on the results of this study and those of previous studies (Nelson, 1938, 1960; Torigoe, 1981; Harry, 1985; Li \& Qi, 1994), the 
anatomical features of the soft organs that can be used to distinguished oyster species within and between genera are: length of epibranchial septa, morpho-sculptural characters of labial palp crests, topography of diverticular openings, configuration of digestive embayments, outlines of caeca, morphology of oesophageal aperture, features of ventricle and auricles, and branches of accessory hearts.

\section{Acknowledgements}

This work was supported in part by George Soros Fund through Prof. Nickolay N. Vorontzov. We are grateful to Toby Bolton for corrections in English and constructive comments, and to Prof. B. Morton for consultation in comparative anatomy of oysters.

\section{References}

Adams, H. \& Adams, A. 1858. The genera of recent Mollusca. Vol. 2 and Vol. 3. Van Voorst, London. 661 pp., 138 pls.

Ahmed, M. 1975. Specialization in living oysters. Adv. Mar. Biol., 13: 357-397.

Arakawa, K.Y. 1990. Commercially important species of oysters in the world. Mar. Behav. Physiol., 17: 1-13.

Awati, P.R. \& Rai, H.S. 1931. Ostrea cucullata (the Bombay oyster). Indian Zool. Mem. Ind. Animal Type, III, Lucknow, Methodist Publ. House, India. 107 pp.

Carreon, J.A. 1968. The malacology of Philippine oystes of genus Crassostrea and review of their shell characters. Proc. Nat. Shellfish. Assoc., 59: 104-115.

Cuvier, G. 1882. Le Regne animal. Mollusques. Fortin, Masson et Comp., Paris. pp. 181-236.

Dahmen, P. 1923. Anatomie von Ostrea chilensis Philippi. Jenaische Zeitschr. Naturwiss., 59: 575626.

Dinamani, P. 1967. Variations in the stomach of the Bivalvia. Malacology., 5(2): 225-268.

Galtsoff, P.S. 1964. The American oyster Crassostrea virginica Gmelin. Fish. Bull., 64, Govern. Print. Office, Washington. $480 \mathrm{pp}$.

Graham, A. 1949. The molluscan stomach. Trans. Roy. Soc. Edinburgh, 61(3): 737-778.

Habe, T. 1977. Systematics of Mollusca in Japan. Bivalvia and Scaphopoda. Hokuryukan Publ. Co., Tokyo. 372 pp. [In Japanese]

Harry, H.W. 1981. Nominal species of living oysters during the last fifty years. Veliger, 24(1): 3945.

Harry, H.W. 1985. Synopsis of the superspecific classification of living oysters (Bivalvia: Gryphaeidae and Ostreidae). Veliger, 28(2): 121- 158.

Hirase, S. 1930. On the classification of Japanese oysters. Jap. J. Zool., 3(1): 1-66.

Hopkins, A.E. 1934. Accessory hearts in the oyster Ostrea gigas. Biol. Bull., 67: 346-355.

Kellogg, J.L. 1892. A contribution to our knowledge of the morphology of lamellibranchiate mollusks. Bull. U.S. Fish. Commiss., 10: 389-436.

Lamarck, J. 1819. Histoire Naturelle des Animaux Sans Vertebres. Tome 6(1). Verdiere, Paris. $343 \mathrm{pp}$.

Leenhart, H. 1926. Quelques etudes sur "Gryphea angulata" (Huitre du Portugal). Ann. de l'Instit. Oceanogr., n.s., 3: 1-89.

$\mathrm{Li}$, Xiaoxu. 1989. A comparative morphology of mantle cavity in some Chinese oysters. Oceanol. Limnol. Sinica, 20(6): 502-507.

Li, X.X. \& Qi, Z.Y. 1994. Studies on the comparative anatomy, systematic classification and evolution of Chinese oysters. Studia marina sinica, 35: 143-178.

Menzel, R.W. 1973. Hybridization in oysters (Crassostrea). Malacol. Rev., 6: 179.

Nelson, T.C. 1938. The feeding mechanism of the oyster. I. On the pallium and branchial chambers of Ostrea virginica, $O$. edulis and $O$. angulata with comparisons with other species of the genus. J. Morphol., 63(1): 1-61.

Nelson, T.C. 1960. The feeding mechanism of the oyster. II. On the gills and palps of Ostrea 
edulis, Crassostrea virginica and C. angulata. J. Morphol., 107: 163-191.

Newball, S. \& Carriker, M.R. 1983. Systematic relationship of the oysters Crassostrea rhizophorae and $C$. virginica: a comparative ultrastructural study of the valves. Bull. Amer. Malacol. Union, $1: 35-42$.

Orton, J.H. 1937. Oyster biology and oyster culture, being the Buckland lectures to 1935. Edward Arnold Co., London. $211 \mathrm{pp}$.

Pelseneer, P. 1903. La classification des Lamellibranches d'apres les branchies. Ann. Soc. Zool. Malacol. Belgique, 38: 58-60.

Purchon, R.D. 1957. The stomach in Filibranchia and Pseudolamellibranchia. Proc. Zool. Soc. London, 129(1): 27-60.

Rodriguez, Z.G.C. \& Garcia-Cubas, A. 1986. Taxonomia y anatomia comparada de las ostras an las costas de Mexico. Ann. Inst. Ciencias Mar. Limnol. Univ. Nac. Autonomia Mexico, 13(2): 249-314.

Rodriguez, Z.G.C. \& Linares, F.A. 1992. Contribution on the taxonomy of the Ostreidae (Mollusca: Bivalvia) in Mexico. Unitas Malacologica, 11th Int. Malacol. Congr., Siena, Italy, 1992, Abstr. Publ. Univ. Siena, Italy: 400-401.

Show, B.L. Battle, H.J. 1957. The gross and microscopic anatomy of the digestive tract of the oyster Crassostrea virginica. Can. J. Zool., 35: 325-347.

Takatsuki, S. 1949. Oyster. Gihoudo Publ. Co., Tokyo. 262 pp. [In Japanese]

Tchang, Si \& Lou, Tze-Kong. 1956. A study on Chinese oysters. Acta Zool. Sinica, 8(1): 65-94.

Torigoe, K. 1981. Oysters in Japan. J. Sci. Hiroshima Univ., B1, 29(2): 291-419.

White, C.A. 1883. A review of the fossil Ostreidae of North America. Ann. Rept. U.S. Geol. Surv., Washington, 4: 279-430.

Yonge, C.M. 1960. Oysters. Collins Clear-Type Press, London. 209 pp. 